\title{
The Donation Response to Natural Disasters
}

\author{
Sarah Smith \\ Mark Ottoni-Wilhelm \\ Kimberley Scharf \\ Discussion Paper 17 / 688 \\ 22 September 2017 \\ BRISTOL \\ Department of Economics \\ University of Bristol \\ Priory Road Complex \\ Bristol BS8 1TU \\ United Kingdom
}




\title{
The donation response to natural disasters ${ }^{i}$
}

Sarah Smith (University of Bristol)

Mark Ottoni-Wilhelm (IUPUI and IU Lilly Family School of Philanthropy)

Kimberley Scharf (University of Birmingham)

\begin{abstract}
Natural disasters, such as the 2004 East Asian Tsunami, attract a high level of donations. Previous literature has shown that the scale of the disaster is important in driving the aid response, but there are inconsistent findings on whether the number killed or the number affected matters more. In this paper we discuss a number of issues in linking measures of the scale of a disaster to the aid response, particularly taking account of outliers in both scale of disaster and aid. We show that a log-specification is preferred and that this specification can reconcile findings based on different datasets. Both the number killed and the number affected matter equally for whether aid is given; the number killed is more strongly related to the magnitude of the aid response. We also present new evidence confirming the importance of publicity for disasters, focusing on appeals.
\end{abstract}




\section{Introduction}

On $26^{\text {th }}$ December 2004 a massive earthquake occurred in the Indian Ocean near the west coast of Sumatra. It sent killer waves radiating from its epicentre causing an estimated 250,000 deaths and affecting an estimated 5 million people across 14 countries. There was an unprecedented public response in the aftermath of the tsunami, not only in the amount of money raised ( $£ 10$ billion globally), but also in the speed with which money was pledged or donated. In the UK, an emergency appeal was launched on 29 December 2004 and set a new world record for the amount donated online in a 24-hour period. $£ 392$ million was donated to the official disaster appeal in the UK - nearly three times the amount raised by any other emergency appeal in the same period of time, before or after. In this paper, we study donor responses to this type of emergency situation caused by natural disasters. We shed light on what determines the magnitude of responses to disaster appeals - focusing on the scale of the disaster and the role of disaster appeals.

Previous literature has used two measures of the scale of the disaster - the number of people reported killed and the number of people reported affected. The latter includes the number with physical needs, such as accommodation, as well as the number injured (Stromberg, 2007; Eisensee and Stromberg, 2007; Evanglidis and Van den Bergh, 2013). Looking to the findings from previous studies, there are seemingly inconsistent results on the relative importance of these two dimensions in driving aid responses to disasters. Stromberg (2007) found that both measures - the number of people killed and the number of people affected-were correlated with whether governmental aid was given in response to a disaster. In contrast, Evangelidis and Van den Bergh (2013) found that only the number killed mattered, not the number affected, for private voluntary (non-governmental) aid, both for whether aid was given and also for the amount of aid. Evangelidis and Van den Bergh (2013) 
argue that the number affected better captures the extent of need that donors should be responding to.

In this paper, we investigate further the relationship between the scale of the disaster measured by the two indicators - and the aid response. We show that the results are sensitive to the functional form specification and we argue in favour of including the number killed and the number affected in logs rather than levels. One reason why the regression results are sensitive to specification is because there are a number of very large scale disasters, including the East Asia Tsunami, which are associated with a high level of impact in terms of the number of people killed and/or the number of people affected and also associated with a big donor response. We show that it is important that estimation take proper account of such "big disasters". With a specification that includes donations and disaster scale in logs, we are able to reconcile the findings from the earlier studies, both with each other - and also with results from a new source of data on the responses to emergency appeals launched by the UK Disaster Emergency Committee (DEC). ${ }^{\text {ii }}$ The consistent findings are that both the number killed and the number affected matter equally for whether aid is given. The number killed has a stronger effect than the number affected on the amount given - and a few of the deadliest disasters have a particularly powerful effect.

We then discuss one factor that may explain the people affected-donation association being smaller, relative to the people killed-donation association: error in measuring the number of people killed. It may be that the number or people killed gives donors a clearer sense of the devastating impact of the disaster that is more directly comparable across disasters.

A second factor is media coverage. Media coverage played an important part in the big response to the East Asia tsunami. Dramatic pictures of devastation were broadcast around the world at Christmas, a time that people typically watch a lot of television and also 
when there may be few competing news stories. ${ }^{\text {iii }}$ Of course, large disasters are more likely to be covered in the media, so to pin down the effect of media coverage, Eisensee and Stromberg (2007) use an instrumental variable approach, exploiting competing news events to instrument coverage of disasters, to show that television coverage has a causal effect on whether aid is provided in the case of natural disasters. Brown and Minty (2008) find a similar effect. The exact mechanism is not clear, but media coverage is likely to provide information on the scale of the need, make the need salient, create identifiable victims by showing images of real people who are suffering (Loewenstein \& Small, 2007) and reduce the social distance between donor and potential recipients (Fong and Luttmer, 2007). Focusing on the DEC appeals, we present new evidence on the importance of public appeals in driving donations. We present stylized facts on donor responses to disaster appeals, exploiting a uniquely detailed dataset that allows us to track donations day-by-day around the time that the appeal is launched. We present striking evidence that appeals have an immediate and powerful effect on donations to DEC and its member charities. Moreover, we pin down the timing of the response to show that it is linked to the date of the appeal, rather than to the date of the disaster itself.

The plan of the paper is as follows. In the next section we discuss data sources that have been used in this literature to estimate the relationship between scale and donation response. In section 3 we revisit existing studies and look at whether we are able to reconcile findings, paying close attention to functional form specifications. Section 4 presents new evidence on the dynamics of donor responses to disaster appeals. Section 5 concludes.

\section{Data and estimation issues}

A key source of data in this literature is the Centre for Research on the Epidemiology of Disasters (CRED) which provides comprehensive coverage of disasters via their Emergency 
Disaster Database (EM-DAT). This dataset records a "disaster" if ten or more people are reported killed or 100 or more people are reported affected, or if a disaster is declared.

CRED reports the number of deaths following each disaster, defined as both the number reported dead and the number reported missing presumed dead. These numbers are based on official measures where available. CRED also reports the number of people who are affected by each disaster, defined as the number of people requiring immediate assistance during a period of emergency, i.e. requiring basic survival needs such as food, water, shelter, sanitation and immediate medical assistance. For many disasters both the number of people killed and number of people affected are estimated - in the immediate aftermath of major disasters it may not be possible to collect precise information on the number killed/ affected.

Table 1 presents summary information from CRED on the number reported killed and the number reported affected for all natural disasters over the period $1968-2015$. As might be expected, the number of people reported killed is typically smaller than the number of people reported affected - only in three per cent of disasters is the relationship the other way round. Perhaps surprisingly, the number killed and the number affected are not strongly correlated $(\rho=0.037)$. This means that it should be possible to identify the separate effects of the two measures of scale on the donation resonse. The strength of the relationship between the two measures of scale does vary considerably across types of disasters, however. The correlation is stronger for landslides, earthquakes and floods and weaker for extreme temperature and wildfire. This makes it important to control for disaster type when looking at the relationship between different measures of disaster scale and the aid response.

Table 1 draws attention to another feature of the scale of disasters - that some disasters stand apart from the others in terms of the numbers of people killed and affected. The mean number killed across all reported natural disasters is around 500, but the worst disasters are associated with the deaths of hundreds of thousands of people. Similarly, the mean number 
affected is just under one million, but the worst disasters affect more than three hundred times that number. The presence of such outliers is likely to make estimation of the effect of scale of the disasters sensitive to functional form specification. Appendix A lists the worst twenty disasters over this period, defined by the number of people killed and, separately by the number of people affected. The profiles of the type and location of the very worst disasters are different depending on the measure used. Strikingly, there is no overlap in the two lists of the worst twenty disasters.

There are also outliers looking at the amounts of aid given - some disasters attract many times more aid than others (see, for example, the set of DEC disaster appeals summarized in Appendix B). This is a potential issue when it comes to looking at the magnitude of the aid response. Stromberg (2007) and Eisensee and Stromberg (2007) look only at whether aid is provided in response to a disaster, focusing on aid provided by the US Office of Foreign Disaster Assistance (OFDA) over the period 1968 - 2002. By contrast, Evangelidis and Van den Bergh (2013) look both at whether aid is given and also at the amount of aid. They exploit information on private donor responses from the Financial Tracking System of UN Office for the Co-ordination of Humanitarian Aid (OCHA). They study a much smaller sample than Stromberg (2007) and Eisensee and Stromberg (2007), focusing on 381 disasters over the period 2000 - 2011 for which aid was given in 124 cases. In this paper, we present new analysis of the amount of aid given, focusing on the appeals launched in the UK by DEC. Over the period 1968 - 2015, DEC launched 65 appeals - Appendix B gives full details. All DEC appeals result in some aid being given and our analysis therefore focuses on what determines the amount that is raised by each appeal. Although a relatively small sample, it allows for comparison with the Evangelidis-Van den Bergh data.

A number of implications follow for any empirical analysis that attempts to relate the scale of disasters to aid given. First, estimating the effect of the number killed and of the 
number affected is going to be affected by a few very big disasters (and these very big disasters will differ according to the two measures of scale). Second, the disasters associated with the most aid will influence estimates regardless of specification. In the next section we show that, indeed, regression results are sensitive to functional form specification and, in the case of amount of aid, to specific high-aid disaster appeals.

\section{Reconciling estimates on aid responses}

\section{Whether aid is given}

The studies by Stromberg (2007) and Evangelidis and Van den Bergh (2013) examine the relationship between the scale of the disaster and whether or not aid is given. The main regression results from Stromberg (2007) are repeated in Table 2; they show that that whether or not aid is given is correlated with both the number killed and the number affected. These numbers are expressed on a $\log 10$ scale. In the OLS specification in column 1, a change in the number killed has a stronger effect on aid than a change in the number affected. This specification includes a control for news coverage. In the IV specification, where news coverage is instrumented with the presence of competing news, the relationship is reversed and the effect of number killed becomes insignificant. The results indicate that part of the observed effect of the number killed is likely due to the fact that deaths drive news coverage.

Evangelidis and Van den Bergh (2013) include the number killed and the number affected in levels in their regression specification. Column 1, Table 3 replicates their approach:iv Whether or not aid is given is regressed on the number killed, the number affected (in units of 100,000s) and an indicator for whether an appeal was launched. The regression also controls for location and type of disaster. In this level- specification, the number of people killed is associated with the probability that there are private voluntary donations in response to the disaster, but the number of people affected is not. On the face of it, these results appear at odds with Stromberg's findings. However, when the same 
relationship is estimated using a log specification (column 2), both the numbers of people killed and affected are associated with the probability of donations, a qualitatively similar set of findings to those of Stromberg (2007).

There are a number of reasons for preferring a log specification. Theoretically, the difference in aid in response to 1,000 additional people killed between one disaster and another, both of whose scale of people killed is in the hundreds, would be expected to be larger a priori than would be the difference in aid in response to 1,000 additional people killed between one disaster and another, both of whose scale of people killed is in the hundreds of thousands. Empirically, formal tests indicate that including measures of the scale of disaster in logs provides a better description of the data. The $R^{2}$ in the log specification is much higher, .275 compared to .206 , indicating that the log specification is a much better description of the whether-aid-is-given-scale relationship. This is confirmed by the $J$-test: although the level model does provide some evidence against the log model $(p=.061)$, the log model provides much stronger evidence against the level model $\left(p=.0004 \times 10^{-6}\right)$.

\section{How much aid is given}

Next we focus on the relationship between the scale of the disaster and how much aid is given. As previously discussed, there are outlying observations both in the distribution of the amount of aid, as well as in the numbers killed/affected; ideally the regression specification will be robust to these outliers. Table 4 uses the Evangelidis-Van den Bergh data to explore the effect of different specifications: The top and bottom panels contain level and log specifications respectively. Across the columns we drop potentially influential observations to investigate how this affects both the estimated coefficients and the specification tests. The estimation is OLS on the sub-sample of 124 disasters where aid was given. The specification tests are comparisons of $R^{2} \mathrm{~s}$. For the $\log$ model, the " $R^{2}$ " is the squared-correlation coefficient between the predicted amount donated in levels and the actual amount donated. 
The first column drops no observations. The level specification in the top panel produces estimates similar to those presented by Evangelidis and Van den Bergh (2013). For every person killed donations are $\$ 9,254$ higher; for every person affected donations are four dollars lower (n.s.). The $R^{2}$ is .635. In the log specification in the bottom panel, aid is also more responsive to the number killed than to the number affected, but the association with the number of people affected is in the expected positive direction and the gap is smaller: A 10 percent increase in the number of people killed is associated with a 4.71 percent increase in donations, a 10 percent increase in the number of people affected is associated with a smaller 1.23 percent increase in donations $(p=.148)$.

Comparing the $R^{2} \mathrm{~S}$ would at first suggest that the level specification is preferred. However, the estimates from the level specification change considerably upon dropping the 2004 East Asian tsunami (the biggest disaster in terms of amount of aid). The people killeddonation association drops by more than half and the appeal-donation association becomes counterintuitively negative. The people affected-donation association remains essentially zero. Also note the large decrease in the standard errors. The estimates from the log specification also change, but by much less. And the standard errors are stable. The $R^{2}-\log$ is now larger than the $R^{2}$-level (.817 compared to .637).

The level results continue to change (both the estimated coefficients and the $R^{2}$ ) upon dropping other high-aid disasters, including the 2010 Haitian earthquake in column 3. Changes in the log specification are much more modest. Overall, the greater insensitivity of the log specification to the influential observations, its sensible positive (borderline significant) estimate for the people affected-donation association, its sensible positive significant appeal-donation association, and its larger $R^{2}$ suggests it is the better of the two specifications. To be sure, in the log specification the people killed-donation association remains larger than the people affected-donation association and the difference is significant 
(see the penultimate row in the Table 12.4). That said, the people affected-donation association is not irrelevant.

These results highlight that high-aid disasters are influential in the estimation. Even in the log specification, the estimate falls by about one-third (.471 to .338) upon dropping four influential observations. This motivates re-estimation of the log specification, using a spline for both the number of people killed and the number of people affected. For the spline in the number of people killed the knot is placed at the point of separation between the eight stand out disasters in the Evangelidis-Van den Bergh sample and the remaining 116. The knot for the spline in the number of people affected is placed to separate out the nine stand out disasters; it turns out that only five of these received donations to help the victims. ${ }^{\mathrm{v}}$

Table 5 presents the estimates for the spline specification. Column 1 reproduces Table 4 (Column 1, panel b) to ease comparison. The spline in the logs specification indicates that donated amounts increase by 15.05 percent in response to a 10 percent increase in the number of people killed among the most deadly disasters, a much larger response than the 2.57 percent increase in response among the less deadly disasters. The difference in response is significant $(p=.0001)$. The same pattern occurs in the response to the number of people affected: larger percentage donated amount responses are associated with percentage increases in the number of people affected among disasters that affect larger numbers of people. The adjusted $-R^{2} \mathrm{~S}$ indicate that the spline improves the model fit: .596 compared to .545 .

For further evidence on the donation response to disasters, we look to confirm the main patterns from the Evangelidis-Van den Bergh data using a dataset on responses to the DEC appeals. This is narrower in scope than the Evangelidis-Van den Bergh data because the DEC data only record disasters for which there was an appeal. There were 33 DEC appeals for natural disasters over the period from 1968 - 2015 for which we also have data on the 
numbers of people killed and affected. Results for this sub-sample DEC sample are reported in Table 6.

For comparison, we repeat the results from Table 4 (Column 1, panel b) for the Evangelidis-Van den Bergh data. In column 2 we also report results for a sub-group of 37 disasters in the Evangelidis-Van den Bergh for which an appeal was launched - this is more directly comparable with the DEC appeal data (although these disasters occurred 2003 2011). Note that the magnitude of the coefficients increases in the sub-sample compared to the full sample, consistent with a stronger response to larger disasters/ appeals. Column (3) reports results for the DEC data that confirm previous findings that the number killed has a stronger effect on the amount of aid than the number affected. The magnitude of the coefficients is smaller than the Evangelidis-Van den Bergh data. Columns (4) and (5) drop the two largest disasters from the analysis. The effect of the number of killed is reduced, confirming that deadly disasters have a particularly powerful effect on donations. The gap in the estimated coefficients on the number killed and the number affected is also reduced, although the significance of the individual coefficients does not change.

Summing up our analysis of the response to disasters, several key insights emerge: First, the presence of outliers makes estimation of the effect of disaster scale on aid sensitive to regression specification. Second, log-specifications are more stable than levelspecifications and are generally preferred on the basis of theoretical considerations and formal specification tests. ${ }^{\text {vi }}$ Third, whether any aid is given depends both on the number of people killed and on the number of people affected - and both measures of the scale of a disaster have a similar relationship. Finally, how much aid is given is more strongly affected by the number killed than the number affected. The number of deaths has a particularly strong effect among a small number of very deadly disasters. 
Evangelidis and Van den Bergh (2013) argue that the stronger effect of the number killed (compared to the number affected) is an indication that aid is mis-directed since, in their view, the number affected provides a stronger indication of the level of need following a disaster than the number killed. A plausible alternative explanation for the smaller association with the number affected may be that this number is harder to measure accurately (compared to the number killed), and that consequently the regression estimate on the number of people affected is attenuated by measurement error. CRED reports that there may be uncertainty about what the number affected even captures: "The indicator affected is often reported and is widely used by different actors to convey the extent, impact, or severity of a disaster in nonspatial terms. The ambiguity in the definitions and the different criteria and methods of estimation produce vastly different numbers, which are rarely comparable." In the aftermath of a major disaster it may be hard to collect comprehensive information on the number killed, let along all the people who may be affected. Guha-Sapir and Below (2002) compared measurements of the numbers of people killed and affected from three studies and found that the studies agreed much more closely in their measurements of the number of people killed than in the number of people affected. This means that it may be harder to identify the underlying relationship with the number affected than with the number killed.

To the extent that the number killed does have a stronger effect on donations than the number affected, one contributory factor is likely to be media coverage. As shown by the results from Eisensee and Stromberg (2007) the number of deaths appears to be more strongly related to media coverage than the number affected and media coverage has a causal effect on the aid response. In the next section, we present new evidence confirming that public appeals play a crucial role in driving donations. 


\section{The importance of publicity}

We provide detailed insight into the week-by-week response of donations to public appeals, focusing on DEC appeals. The decision by DEC to launch an appeal triggers a set of actions by the Rapid Response Network. Specifically, national banks and the Post Office network are set up to receive donations; appeal videos, often featuring well-known celebrities, are broadcast via national news networks. Although the disasters will have been in the news, the appeals give the disasters - and the need for funds - additional nationwide visibility. We show that these appeals are important in driving donations.

We track donations before and after the launch of a DEC appeal on a high frequency basis. We do this by exploiting anonymized data on donations made through charity accounts administered the Charities' Aid Foundation (CAF) ${ }^{\text {vii }}$ Important for our analysis, we observe the exact date of donations - as well as the recipient charity - for a panel of more than 100,000 donors. Over the period 2009-2015, six disaster appeals were launched by DEC. viii

We report average responses to these six appeals; further analysis confirms that responses are similar across the six appeals. Tracking donations on a high frequency basis allows us to study dynamics in the response to appeals. We also show that the appeal is crucial in triggering a response among donors: specifically, the timing of the response is linked to the date of the appeal, not the date of the disaster itself.

Figure 1, reproduced from Scharf, Smith and Ottoni-Wilhelm (2017), shows the dynamics in the response to appeals. The figure plots the estimated coefficients (and confidence intervals based on robust standard errors) associated with indicators for the weeks before and after the DEC appeal is launched. Weeks are defined as seven-day periods relative to the exact date of the appeal; week 0 indicates the first seven days after the appeal is launched. The coefficients capture differences in daily donations to DEC ( + the thirteen member charities) during the weeks before/ after the appeal, compared to baseline, i.e. outside the 
disaster periods. ${ }^{\text {ix }}$ We track donations through to week 19 (i.e. twenty-weeks after the appeal) which allows sufficient time for the response to the appeal to play out.

The pattern of coefficients and standard errors indicates that there are distinct phases in the response to appeals.

- Phase 1 (weeks 0-4) is the aftermath period during which there is an immediate and strong response to the appeal. In the seven days following a disaster appeal, average daily donations to the DEC-13 are more than seven times $\left(e^{2.09}-1=7.08\right)$ higher than average daily donations to the DEC-13 during non-disaster period (i.e, outside the 22 week window surrounding each of the six disaster appeals) and around four times higher during the following three weeks $\left(e^{1.49}-1=3.44 ; e^{1.66}-1=4.26\right){ }^{\mathrm{x}}$

- Phase 2 (weeks 5-9) is an adjustment period: donations to DEC-13 are still above their usual level, but lower than during the immediate aftermath and beginning to return to their baseline level.

- Phase 3 (weeks 10-14) is a settling period: donations to DEC-13 are very close to baseline with no clear direction of movement.

- Phase 4 (weeks 15-19) marks a complete return to baseline: the effect of the disaster appeal appears to have played out.

The results indicate that the response is initially strong but plays out fairly quickly, with donations returning to their baseline level after a period of around two months. ${ }^{\text {xi }}$ This indicates that high-frequency data are important for looking at donation responses to this type of appeal. ${ }^{\text {ii }}$

There is no evidence that the appeal causes time-shifting in donations to DEC-13 i.e. that the increase in donations in the aftermath of an appeal is offset by any reduction in donations to the same charities at a later point in time, either during the twenty-week period 
or subsequently. Instead, the appeal is associated with a significant increase in donations to DEC-13, compared to baseline. ${ }^{\text {xii }}$

This analysis of the effect of the DEC appeals focuses on the date of the appeal, rather than the date of the disaster. This is consistent with the actual pattern of responses. We test this by looking for an effect of the date of the disaster, rather than the date of the appeal. Four of the DEC appeals during the sample period were associated with a natural disaster that occurred on a specific date. Since there is typically a lag between the date of the disaster and the date of the appeal (between three and six days), this allows us to test whether contributions respond to the disaster or to the appeal by repeating the analysis, but including an additional indicator variable for days after the date of the disaster, before the appeal is launched. The coefficient on this indicator variable is relatively small and insignificant: 0.165 (0.345). This contrasts with the very strong positive response to the appeal during the first seven days. Therefore, we can dismiss that donations build up gradually after the disaster, because the response is immediate and large after the appeal, but not before. This provides striking evidence on the effect of public appeals in driving contributions.

\section{Discussion and conclusions}

Natural disasters often trigger strong donation responses. We show that the magnitude of the response is linked to the scale of the disaster, particularly as measured by the number killed. Our interpretation of this finding is that the number killed provides a more reliable - and directly comparable - measure of the severity of the disaster. Analysing high-frequency data on donations, we show that the appeals are important in triggering a donation response. The response to appeals is strong and immediate, but relatively short-lived and tends to have played out after two-three months. The evidence also suggests that appeals generate new funding for international aid, with no time-shifting in donations to DEC-13. 
References

Brown, P. and J. Minty (2008) "Media coverage and charitable giving after the 2004 tsunami” Southern Economic Journal, 75 9-25

Eckel, C., Grossman, P. and A. Oliveira. (2007) "Is More Information Always Better? An Experimental Study of Charitable Giving and Hurricane Katrina" Southern Economic Journal 74 (2) 388-411.

Eisensee, T. and Stromberg, D. (2007) "News Floods, News Droughts and US Disaster Relief' Quarterly Journal of Economics 122(2) 693 - 728

Evangelidis, I. \& Van den Bergh, B. (2013). The number of fatalities drives disaster aid: Increasing sensitivity to people in need. Psychological Science, 24 (11), 22262234 .

Fong, C. and Luttmer, E. (2007) "What Determines Giving to Hurricane Katrina Victims? Experimental Evidence on Racial Group Loyalty." American Economic Journal: Applied Economics 1(2) $64-87$.

Loewenstein, G., \& Small, D. A. (2007) "The scarecrow and the tin man: The vicissitudes of human sympathy and caring." Review of General Psychology 11(2): 112-126.

Scharf, K., Smith, S. and Ottoni-Wilhelm, M. (2017) Lift or shift: The effect of fundraising interventions in charity space and time Mimeo

Stromberg, D. (2007) "Natural Disasters, Economic Development and Humanitarian Aid" The Journal of Economic Perspectives 21 (3) 199 - 222.

Wiepking, P., \& van Leeuwen, M.H.D. (2013). Picturing generosity: Explaining the success of national campaigns in the Netherlands. Nonprofit and Voluntary Sector Quarterly, $42,262-284$. 
Table 1

Number reported killed and number reported affected, natural disasters $1968-2015$

\begin{tabular}{|l|ccc|}
\hline & $\begin{array}{c}\text { Number of people } \\
\text { killed }\end{array}$ & $\begin{array}{c}\text { Number of people } \\
\text { affected }\end{array}$ & Correlation \\
\hline Mean (SD) & 477 & 927,508 & 0.037 \\
\hline Min & $(7,528)$ & $(8,897,949)$ & \\
\hline Max & 0 & 0 & \\
\hline By type (mean) & 300,317 & $300,000,000$ & 0.012 \\
Drought & 1,156 & $3,560,346$ & 0.275 \\
Earthquake & 2,005 & 280,759 & 0.102 \\
Epidemic & 253 & 27,392 & -0.006 \\
Extreme temp & 412 & 233,247 & 0.241 \\
Flood & 123 & $1,499,187$ & 0.379 \\
Landslide & 85 & 22,086 & 0.076 \\
Storm & 494 & 591,101 & 0.002 \\
Volcano & 160 & 38,364 & -0.003 \\
Wildfire & 7 & 22526 & 12740 \\
\hline N & 12470 & 12470 & \\
\hline
\end{tabular}

Source: Data on natural disasters from EM-DAT, provided by the Centre for Research on the Epidemiology of Disasters (CRED)

\section{Table 2}

\section{Stromberg's (2007) results}

Dependent variable: Whether aid is provided in response to a natural disaster $(0 / 1)$

\begin{tabular}{|l|c|c|}
\hline & OLS & IV \\
\hline Number killed $(\log 10)$ & $0.10^{* * *}$ & 0.02 \\
& $(0.01)$ & $(0.04)$ \\
\hline Number affected $(\log 10)$ & $0.06^{* * *}$ & $0.04^{* * *}$ \\
& $(0.01)$ & $(0.01)$ \\
\hline Real GDP per capita $(\log 10)$ & $-0.08^{* * *}$ & $-0.23^{* * *}$ \\
& $(0.03)$ & $(0.07)$ \\
\hline Disaster in the news $(0 / 1)$ & $0.09^{* * *}$ & $0.76^{* *}$ \\
& $(0.02)$ & $(0.32)$ \\
\hline
\end{tabular}

Notes to table: These results are taken from Stromberg (2007). Regressions additionally control for year, continent, disaster type and month and for (log) population. Disaster in the news is instrumented with presence of competing news stories (eg Olympics). Robust standard errors, clustered by recipient country in parentheses.

* denotes significant at 10 per cent, ** 5 per cent, *** 1 per cent. 
Table 3

\section{Replication of Evangelidis and Van den Bergh's (2013) level-specification, and new results in logs}

Dependent variable: Whether aid is provided in response to a natural disaster $(0 / 1)$

\begin{tabular}{|c|c|c|}
\hline & $\begin{array}{c}\text { OLS } \\
\text { Levels }\end{array}$ & $\begin{array}{l}\text { OLS } \\
\text { Logs }\end{array}$ \\
\hline Number of people killed $\left(\beta_{1}\right)$ & $\begin{array}{l}.118^{a, b} \\
(.075)\end{array}$ & $\begin{array}{l}.041^{* * *} \\
(.012)\end{array}$ \\
\hline Number of people affected $\left(\beta_{2}\right)$ & $\begin{array}{c}.0001^{a} \\
(.0002)\end{array}$ & $\begin{array}{l}.030^{* * *} \\
(.010) \\
\end{array}$ \\
\hline Appeal & $\begin{array}{l}.544^{* * *} \\
(.067)\end{array}$ & $\begin{array}{l}.408^{* * *} \\
(.068)\end{array}$ \\
\hline p-value: $\left(\beta_{1}=\beta_{2}\right)$ & .115 & .546 \\
\hline$R^{2}$ & .206 & .275 \\
\hline$J$-test evidence against the model $t$-statistic & 6.392 & -1.879 \\
\hline$p$-value & $.0004 \times 10^{-6}$ & .061 \\
\hline$N$ & 381 & 381 \\
\hline
\end{tabular}

Notes: Estimates are from linear probability models. In column 1 the numbers of people killed and affected are in levels; in column 2 the numbers are in logarithms. Both specification include controls for continent, disaster type and year trend. ${ }^{* * *} p<.01$. ${ }^{a}$ Numbers in units of 100,000s. For example, and additional 100,000 people killed is associated with a .118 point increase in the probability of donations. ${ }^{b} p=.114$. Data source:

Evangelidis and Van den Bergh (2013). 
Table 4: Level and log specifications, with specification tests. Dependent variable $=$ How much aid is provided $(>0)$

\begin{tabular}{|c|c|c|c|c|c|}
\hline & (1) & $(2)$ & (3) & $(4)$ & $(5)$ \\
\hline & None & $\begin{array}{c}\text { Drop } 2004 \text { tsunami } \\
\text { East Asia }\end{array}$ & $\begin{array}{c}\text { Drop } 2010 \text { earthquake } \\
\text { Haiti }\end{array}$ & $\begin{array}{c}\text { Drop } 2011 \text { tsunami } \\
\text { Japan }\end{array}$ & $\begin{array}{c}\text { Drop } 2010 \text { floods } \\
\text { Pakistan }\end{array}$ \\
\hline$N$ & 124 & 123 & 122 & 121 & 120 \\
\hline \multicolumn{6}{|c|}{ a. Level specification } \\
\hline Number killed $\left(\beta_{1}\right)$ & $\begin{array}{l}9,254^{* *} \\
(3,922 .)\end{array}$ & $\begin{array}{l}3,864 . .^{* * *} \\
(1,376 .)\end{array}$ & $\begin{array}{l}1,109 .^{c} \\
(669 .)\end{array}$ & $\begin{array}{l}714 .{ }^{*} \\
(404 .)\end{array}$ & $\begin{array}{l}886 .{ }^{* *} \\
(403 .)\end{array}$ \\
\hline Number affected $\left(\beta_{2}\right)$ & $\begin{array}{l}-4 . \\
(5 .)\end{array}$ & $\begin{array}{l}-1 . \\
(2 .)\end{array}$ & $\begin{array}{c}0 . \\
(1 .)\end{array}$ & $\begin{array}{l}1 . \\
(1 .)\end{array}$ & $\begin{array}{c}0 . \\
(0 .)\end{array}$ \\
\hline Appeal & $\begin{array}{c}7,074,574 . \\
(33,294,007 .)\end{array}$ & $\begin{array}{c}-7,970,189 . \\
(17,887,581 .)\end{array}$ & $\begin{array}{c}1,362,605 . \\
(15,946,616 .)\end{array}$ & $\begin{array}{c}13,518,647 . \\
(10,451,346 .)\end{array}$ & $\begin{array}{c}3,584,683 . \\
(3,106,515 .)\end{array}$ \\
\hline$p$-value: $\left(\beta_{1}=\beta_{2}\right)$ & .020 & .006 & .101 & .081 & .030 \\
\hline$R^{2}$ & .635 & .637 & .183 & .274 & .595 \\
\hline \multicolumn{6}{|l|}{ b. Log specification } \\
\hline Number killed $\left(\beta_{1}\right)$ & $\begin{array}{l}.471^{* * *} \\
(.093)\end{array}$ & $\begin{array}{l}.427^{* * *} \\
(.090)\end{array}$ & $\begin{array}{l}.401^{* * *} \\
(.093)\end{array}$ & $\begin{array}{l}.351^{* * *} \\
(.086)\end{array}$ & $\begin{array}{l}.338^{* * *} \\
(.088)\end{array}$ \\
\hline Number affected $\left(\beta_{2}\right)$ & $\begin{array}{l}.123 \\
(.084)\end{array}$ & $\begin{array}{l}.135^{b} \\
(.084)\end{array}$ & $\begin{array}{c}.129 \\
(.084)\end{array}$ & $\begin{array}{l}.139^{d} \\
(.085)\end{array}$ & $\begin{array}{l}.112 \\
(.083)\end{array}$ \\
\hline Appeal & $\begin{array}{c}1.626^{* * *} \\
(.401)\end{array}$ & $\begin{array}{c}1.514^{* * *} \\
(.387)\end{array}$ & $\begin{array}{c}1.518^{* * *} \\
(.394)\end{array}$ & $\begin{array}{c}1.667^{* * *} \\
(.383)\end{array}$ & $\begin{array}{c}1.598^{* * *} \\
(.379)\end{array}$ \\
\hline$p$-value: $\left(\beta_{1}=\beta_{2}\right)$ & .012 & .023 & .042 & .085 & .071 \\
\hline$R^{2 a}$ & .220 & .817 & .234 & .317 & .607 \\
\hline
\end{tabular}

Notes: OLS estimates using the sample of disasters in which donations were received. All regressions control for continent, disaster type and a year trend. ${ }^{* * *} . p \leq .01,{ }^{* *} p \leq$ $.05,{ }^{*} p \leq .10 .{ }^{a}$ For the log specification the $R^{2}$ is calculated by first predicting the amount donated in levels (using the estimates from the log specification), and then calculating the squared-correlation coefficient with the actual amount donated in levels. ${ }^{b} p=.109 .{ }^{c} p=.101 .{ }^{d} p=.105$. Data source: Evangelidis and Van den Bergh (2013). 


\section{Table 5. Spline specification in logs}

Dependent variable: How much aid is provided $(>0)$

\begin{tabular}{|c|c|c|}
\hline & Linear in $\log s^{c}$ & Spline in logs \\
\hline & $(1)$ & $(2)$ \\
\hline Number of people killed & $\begin{array}{l}.471^{* * *} \\
(.093)\end{array}$ & 2 \\
\hline Number of people killed less than $5,778^{a}$ & . & $\begin{array}{l}.257^{* *} \\
(.102)\end{array}$ \\
\hline Number of people killed above $\quad 5,778$ & . & $\begin{array}{c}1.505^{* * *} \\
(.264)\end{array}$ \\
\hline Number of people affected & $\begin{array}{l}.123^{d} \\
(.084)\end{array}$ & - \\
\hline Number of people affected less than 14 million $^{b}$ & & $\begin{array}{l}.097^{e} \\
(.098) \\
\end{array}$ \\
\hline Number of people affected above 14 million & . & $\begin{array}{c}.726^{e} \\
(.657)\end{array}$ \\
\hline Appeal & $\begin{array}{c}1.626^{* * *} \\
(.401)\end{array}$ & $\begin{array}{c}1.505^{* * *} \\
(.389) \\
\end{array}$ \\
\hline $\mathrm{N}$ & 124 & 124 \\
\hline$R^{2}$ & .593 & .645 \\
\hline adjusted $-R^{2}$ & .545 & .596 \\
\hline
\end{tabular}

Notes: OLS estimates using the sample of disasters in which donations were received $(N=124)$. Both

regressions control for continent, disaster type and a year trend. The $R^{2} s$ are based on the sum of squares of the log amount donated. ${ }^{* * *} p \leq .01,{ }^{* *} p \leq .05,{ }^{*} p \leq .10$. ${ }^{a}$ The number of people killed in the 2006 earthquake in Indonesia. ${ }^{b}$ The number of people affected in the 2007 flood in Bangladesh was 13,771,380. ${ }^{c}$ Estimates repeated from Table B. ${ }^{d} p=.148 .{ }^{e}$ Test of the hypothesis that both coefficients are zero has $p=.116$. 


\section{Table 6. Analysis of DEC appeals}

Dependent variable: How much aid is provided (in logs)

\begin{tabular}{|c|c|c|c|c|c|}
\hline & $\begin{array}{c}\text { (1) } \\
\text { Evangelidis } \\
\text { All }(>0)\end{array}$ & $\begin{array}{c}\text { (2) } \\
\text { Evangelidis } \\
\text { Appeals }\end{array}$ & $\begin{array}{c}\text { (3) } \\
\text { DEC } \\
\text { Appeals }\end{array}$ & $\begin{array}{c}(4) \\
\text { DEC } \\
\text { (drop } \\
\text { Tsunami) }\end{array}$ & $\begin{array}{c}\text { (5) } \\
\text { DEC } \\
\text { (drop Haiti) }\end{array}$ \\
\hline Number killed $\left(\beta_{1}\right)$ & $\begin{array}{c}0.471 * * \\
(0.093)\end{array}$ & $\begin{array}{c}0.779 * * \\
(0.171)\end{array}$ & $\begin{array}{c}0.304 * * \\
(0.105)\end{array}$ & $\begin{array}{c}0.238 * * \\
(0.087) \\
\end{array}$ & $\begin{array}{c}0.225 * * \\
(0.086)\end{array}$ \\
\hline Number affected $\left(\beta_{2}\right)$ & $\begin{array}{c}0.123 \\
(0.084)\end{array}$ & $\begin{array}{c}0.300 \\
(0.203)\end{array}$ & $\begin{array}{c}0.031 \\
(0.220)\end{array}$ & $\begin{array}{c}0.095 \\
(0.175) \\
\end{array}$ & $\begin{array}{c}0.099 \\
(0.171)\end{array}$ \\
\hline Appeal launched $(0 / 1)$ & $\begin{array}{c}1.626 \\
(0.401)\end{array}$ & - & - & - & - \\
\hline$p$-value: $\left(\beta_{1}=\beta_{2}\right)$ & {$[.012]$} & {$[.144]$} & {$[.323]$} & {$[.490]$} & {$[0.530]$} \\
\hline $\mathrm{N}$ & 124 & 37 & 33 & 32 & 31 \\
\hline
\end{tabular}




\section{Figure 1: Estimated response to disasters, by week}

\section{Donations to international relief charities}

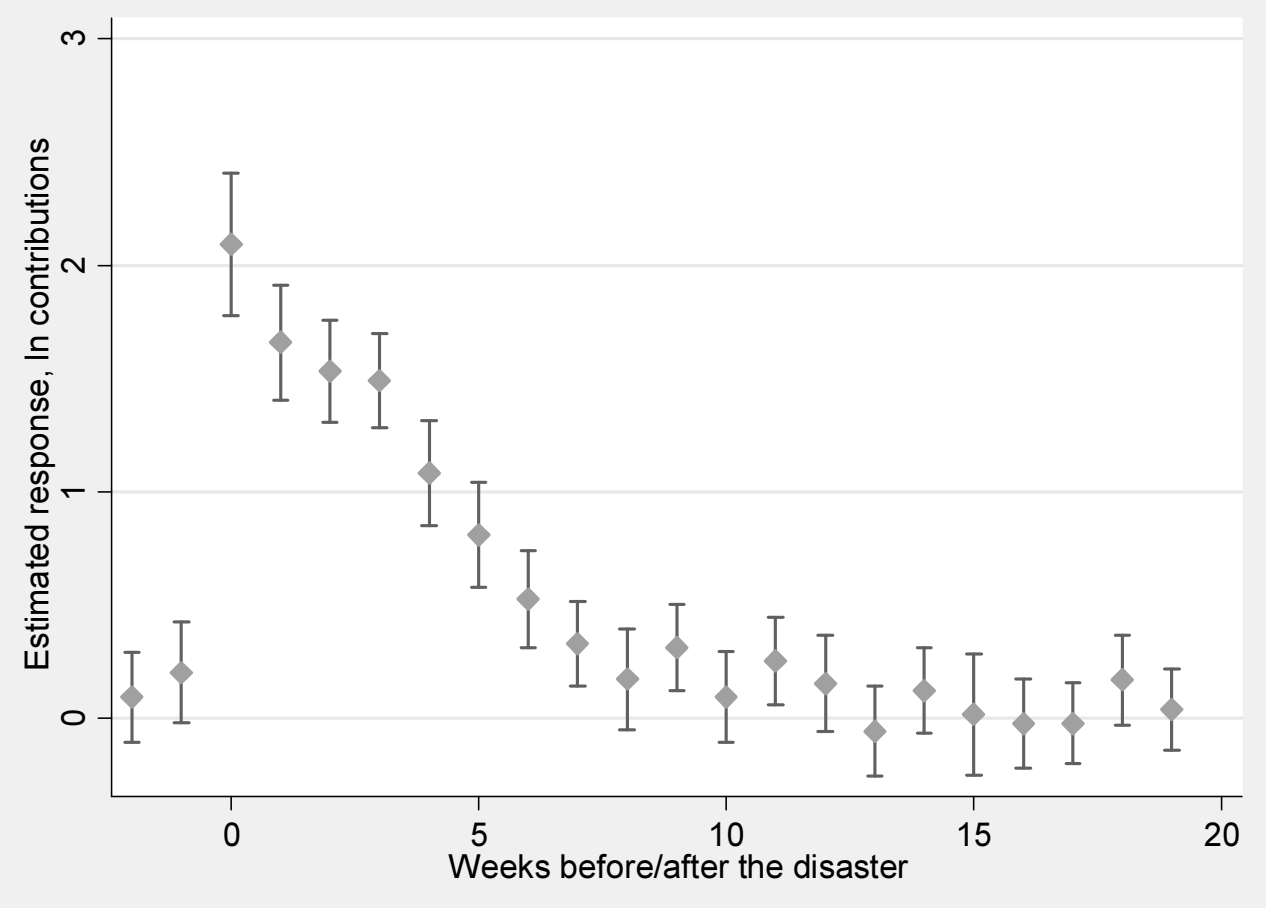

Notes to figure: Difference in daily (In) donations to DEC and 13 member charities, relative to baseline of non-disaster periods. Estimated coefficients plus confidence intervals. Regressions (estimated using OLS) include controls for trend, month, day of month, day of week, Christmas, New Year, Easter, bank holidays and major telethons. Figure taken from Scharf, Smith and Ottoni-Wilhelm (2017). 
Appendix A: Biggest natural disasters, 1968 - 2015 (CRED)

\begin{tabular}{|c|c|c|c|c|}
\hline year & type & Country & Number killed & Number affected \\
\hline \multicolumn{5}{|c|}{ Worst twenty disasters, by number killed } \\
\hline 1970 & Storm & Bangladesh & 300000 & 3648000 \\
\hline 1983 & Drought & Ethiopia & 300000 & 7750000 \\
\hline 1976 & Earthquake & China & 242000 & 164000 \\
\hline 2010 & Earthquake & Haiti & 222570 & 3700000 \\
\hline 2004 & Earthquake & Indonesia & 165816 & 673731 \\
\hline 1983 & Drought & Sudan (the) & 150000 & 8400000 \\
\hline 1991 & Storm & Bangladesh & 138866 & 15438849 \\
\hline 2008 & Storm & Myanmar & 138366 & 2420000 \\
\hline 1973 & Drought & Ethiopia & 100000 & 3000000 \\
\hline 1981 & Drought & Mozambique & 100000 & 4750000 \\
\hline 2008 & Earthquake & China & 87564 & 47437647 \\
\hline 2005 & Earthquake & Pakistan & 73338 & 5128309 \\
\hline 1970 & Earthquake & Peru & 66794 & 3216240 \\
\hline 2010 & Extreme temp & Russian Federation & 55760 & 11 \\
\hline 1990 & Earthquake & Iran & 40021 & 732400 \\
\hline 2004 & Earthquake & Sri Lanka & 35399 & 1019306 \\
\hline 1999 & Flood & Venezuela & 30005 & 543503 \\
\hline 1974 & Flood & Bangladesh & 28700 & 38000000 \\
\hline 2003 & Earthquake & Iran & 26797 & 297049 \\
\hline 1978 & Earthquake & Iran & 25045 & 40052 \\
\hline \multicolumn{5}{|c|}{ Worst twenty disasters, by number affected } \\
\hline 2002 & Drought & India & 0 & 300000000 \\
\hline 1987 & Drought & India & 300 & 300000000 \\
\hline 1998 & Flood & China & 4250 & 242714300 \\
\hline 1991 & Flood & China & 1861 & 210235727 \\
\hline 1972 & Drought & India & 0 & 200000000 \\
\hline 2003 & Flood & China & 662 & 155924986 \\
\hline 1996 & Flood & China & 4091 & 154674000 \\
\hline 2010 & Flood & China & 1911 & 140194000 \\
\hline 1993 & Flood & India & 1297 & 128060000 \\
\hline 1995 & Flood & China & 1618 & 126570411 \\
\hline 2002 & Flood & China & 1246 & 113255696 \\
\hline 1994 & Flood & China & 1564 & 111539385 \\
\hline 2007 & Flood & China & 1030 & 111110792 \\
\hline 2002 & Storm & China & 108 & 107403094 \\
\hline 1999 & Flood & China & 1185 & 107197000 \\
\hline 1989 & Flood & China & 2000 & 100010000 \\
\hline 1982 & Drought & India & 0 & 100000000 \\
\hline 2011 & Flood & China & 628 & 93360000 \\
\hline 1994 & Drought & China & 0 & 88690000 \\
\hline 2008 & Extreme temperature & China & 145 & 77000000 \\
\hline
\end{tabular}


Appendix B: DEC Disaster Appeals (1968 - 2015)

\begin{tabular}{|c|c|c|c|c|c|}
\hline Date & DisasterType & Country & Dead & Affected & Amount \\
\hline Feb 1968 & war & Vietnam & & & 360000 \\
\hline Sept 1968 & earthquake & Iran & 10000 & 79050 & 210000 \\
\hline Nov 1968 & war & Nigeria & & & 240000 \\
\hline Oct 1969 & floods & Tunisia & 616 & 471506 & 90000 \\
\hline Nov 1969 & earthquake & Yugoslavia & 15 & 286116 & 60000 \\
\hline Mar 1970 & earthquake & Turkey & 1086 & 83448 & 370000 \\
\hline Jun 1970 & earthquake & Peru & 66794 & 3216240 & 230000 \\
\hline Jun 1970 & floods & Romania & 215 & 238755 & 110000 \\
\hline Nov 1970 & storm & Bangladesh & 300000 & 3648000 & 1490000 \\
\hline Jun 1971 & war & Pakistan & & & 1420000 \\
\hline Dec 1972 & earthquake & Nicaragua & 10000 & 720000 & 340000 \\
\hline Oct 1973 & drought & Ethiopia & 100000 & 3000000 & 1540000 \\
\hline Sep 1974 & storm & Honduras & 8000 & 600000 & 350000 \\
\hline Feb 1976 & earthquake & Guatemala & 23000 & 4993000 & 1300000 \\
\hline Sep 1979 & war & Cambodia & & & 560000 \\
\hline Nov 1979 & storm & India & 594 & 1605772 & 870000 \\
\hline Jun 1980 & drought & East Africa & & & 6100000 \\
\hline Mar 1982 & war & Central America & & & 430000 \\
\hline Jul 1982 & war & Lebanon & & & 1030000 \\
\hline Mar 1983 & famine & Ethiopia & & & 1970000 \\
\hline Jun 1984 & famine & Africa & & & 9520000 \\
\hline Oct 1984 & famine & Ethiopia & & & 5250000 \\
\hline May 1985 & storm & Bangladesh & 15121 & 1831300 & 1400000 \\
\hline Jun 1987 & war & Mozambique & & & 2480000 \\
\hline Dec 1987 & famine & Ethiopia & & & 2690000 \\
\hline Aug 1988 & flood & Sudan & 96 & 2500000 & 8890000 \\
\hline Sep 1988 & storm & Bangladesh & 2379 & 45000000 & 5810000 \\
\hline Sep 1988 & storm & Caribbean & 103 & 1740000 & 1000000 \\
\hline Dec 1989 & famine & Ethiopia & & & 10240000 \\
\hline Sep 1990 & war & Gulf & & & 3490000 \\
\hline Jan 1991 & famine & Africa & & & 7930000 \\
\hline May 1991 & storm & Bangladesh & 138866 & 15438849 & 3520000 \\
\hline Jun 1991 & famine & Africa & & & 2600000 \\
\hline Sep 1992 & famine & Africa & & & 17300000 \\
\hline Oct 1993 & famine & Africa & & & 2530000 \\
\hline Feb 1994 & war & Yugoslavia & & & 2600000 \\
\hline May 1994 & war & Rwanda & & & 37000000 \\
\hline May 1998 & war & Sudan & & & 10500000 \\
\hline Sep 1998 & floods & Bangladesh & 103 & 1000000 & 5500000 \\
\hline Nov 1998 & storm & Central America & 18808 & 3246628 & 18500000 \\
\hline Apr 1999 & war & Kosovo & & & 53000000 \\
\hline Nov 1999 & storm & India & 9843 & 12628312 & 7000000 \\
\hline Mar 2000 & flood & Mozambique & 800 & 4500000 & 30000000 \\
\hline Feb 2001 & earthquake & India & 20005 & 6321812 & 24000000 \\
\hline
\end{tabular}




\begin{tabular}{|c|c|c|c|c|c|}
\hline Jan 2002 & volcano & DR Congo & 200 & 110400 & 4650000 \\
\hline Jul 2002 & drought & Southern Africa & & & 16000000 \\
\hline Aug 2003 & war & Liberia & & & 2500000 \\
\hline Jul 2004 & war & Sudan & & & 35000000 \\
\hline Dec 2004 & tsunami & Asia & 250000 & 5000000 & 392000000 \\
\hline Aug 2005 & drought & Nigeria & & & 32000000 \\
\hline Oct 2005 & earthquake & India/ Pakistan & 74647 & 5284931 & 59000000 \\
\hline May 2007 & war & Dafur/Chad & & & 13600000 \\
\hline Nov 2007 & storm & Bangladesh & 4234 & 8978754 & 9000000 \\
\hline May 2008 & storm & Myanmar & 138366 & 2420000 & 19500000 \\
\hline Nov 2008 & war & DR Congo & & & 10500000 \\
\hline Jan 2009 & war & Gaza & & & 8300000 \\
\hline Oct 2009 & earthquake & Indonesia & 1202 & 9806076 & 9300000 \\
\hline Jan 2010 & earthquake & Haiti & 222570 & 3700000 & $1.07 \mathrm{E}+08$ \\
\hline Aug 2010 & floods & Pakistan & 2113 & 20363496 & 71000000 \\
\hline Jul 2011 & drought & East Africa & & & 79000000 \\
\hline Mar 2013 & war & Syria & & & 27000000 \\
\hline Nov 2013 & storm & Phillipines & 7354 & 16106870 & 97000000 \\
\hline Aug 2014 & war & Gaza & & & 19000000 \\
\hline Oct 2014 & disease & West Africa & 11310 & 28620 & 37000000 \\
\hline Apr 2015 & earthquake & Nepal & 8969 & 5640265 & 87000000 \\
\hline
\end{tabular}


Comparison of natural disasters and DEC appeals, 1968 - 2015

\begin{tabular}{|c|c|c|c|c|c|}
\hline & \multicolumn{3}{|c|}{ Breakdown of all natural disasters } & \multicolumn{2}{|c|}{$\begin{array}{c}\text { Breakdown of DEC } \\
\text { appeals }\end{array}$} \\
\hline & $\%$ disasters & $\%$ deaths & $\%$ affected & $\begin{array}{l}\text { \#DEC } \\
\text { appeals }\end{array}$ & $\begin{array}{l}\% \text { DEC } \\
\text { appeals }\end{array}$ \\
\hline \multicolumn{6}{|l|}{ By area } \\
\hline Africa & 19.1 & 24.9 & 7.1 & 28 & 43.1 \\
\hline Asia & 35.3 & 50.9 & 86.9 & 20 & 30.8 \\
\hline Australasia & 4.5 & 1.9 & 0.3 & 0 & 0 \\
\hline Central America & 16.8 & 13.8 & 3.8 & 8 & 12.3 \\
\hline Europe & 14.4 & 6.2 & 0.8 & 5 & 7.7 \\
\hline Middle East & 2.7 & 3.5 & 0.8 & 4 & 6.2 \\
\hline North America & 7.3 & 0.5 & 0.4 & 0 & 0 \\
\hline \multicolumn{6}{|l|}{ By type } \\
\hline Drought & 5.0 & 19.4 & 30.6 & 5 & 7.7 \\
\hline Earthquake & 8.3 & 36.8 & 2.6 & 11 & 16.9 \\
\hline Epidemic & 10.7 & 6.5 & 0.4 & 1 & 1.5 \\
\hline Extreme temp & 4.1 & 4.9 & 1.4 & 0 & 0 \\
\hline Flood & 34.6 & 8.2 & 50.8 & 2 & 3.1 \\
\hline Landslide & 5.3 & 1.1 & 0.1 & 0 & 0 \\
\hline Storm & 27.4 & 22.4 & 13.8 & 13 & 20.0 \\
\hline Volcano & 1.6 & 1.0 & 0.1 & 1 & 1.5 \\
\hline Wildfire & 3.1 & 0.1 & 0.1 & 0 & 0 \\
\hline Famine & & & & 9 & 13.9 \\
\hline War & & & & 19 & 29.2 \\
\hline $\mathrm{N}$ & 12470 & 12470 & 12740 & 65 & 65 \\
\hline
\end{tabular}


${ }^{\mathrm{i}}$ Thanks to Ioannis Evangelidis for sharing the data used in his paper written with Bram Van den Bergh. Thanks
also to the Charities Aid Foundation for allowing us access to their anonymized account data. All errors are the authors' own.

${ }^{\text {ii }}$ DEC is an umbrella organisation that brings together thirteen leading UK aid charities to co-ordinate fundraising efforts in times of humanitarian crisis. The thirteen member charities are large international aid charities, including Action Aid, Age International, British Red Cross, CAFOD, Care International, Christian Aid, Concern Worldwide, Islamic Relief, Oxfam, Plan UK, Save the Children, Tearfund and World Vision. Full details of all appeals launched from 1968 - 2015 are given in Appendix B.

iii Viewing data for 2015 and 2016 show roughly 15\% more hours viewed in the days between Christmas and New Year compared to the rest of December/ January (and higher levels of viewing in these months compared to the rest of the year) http://www.barb.co.uk/viewing-data/weekly-viewing-summary/

${ }^{\text {iv }}$ Evangelidis and Van den Bergh adopt a Heckman two-step procedure and use a logit model for the first stage. We use a linear probability model for ease of interpretation but the results are similar.

${ }^{\mathrm{v}}$ In general, there is a high degree of overlap between the biggest disasters in the Evangelidis-Van den Bergh data and those that are reported in Appendix A, although it is not perfect. In some cases, disasters reported separately in EMDAT have been combined (eg Earthquake + Tsuanmi that occurred in Japan).

${ }^{\text {vi }}$ Another example: Wiepking and van Leeuwen (2013) report evidence from Dutch data that the bivariate correlation between the number of people killed in and the amount donated-both in levels—is zero, but using the same data there is a strong correlation in the logarithms (Wiepking, personal communication).

vii Scharf, Smith and Ottoni-Wilhelm (2017) provide more information on the data. CAF is a charity that provides financial services to the sector. Its charity accounts are, in effect, checking accounts for making contributions to charities. Donors set up an account with a minimum $£ 100$ one-off payment or $£ 10$ monthly direct debit, and use the funds to make contributions to any charity in a variety of ways. The rationale for such accounts is that they facilitate tax-effective giving.

viii The appeals were in response to the 2009 September Sumatra earthquake, the 2010 January Haiti earthquake, the 2010 August Pakistan floods, the 2011 east Africa famine, the 2013 Syrian civil war, and the 2013

Philippines typhoon Haiyan. See Appendix B.

${ }^{\text {ix }}$ Further tests reported in Scharf, Smith and Ottoni-Wilhelm (2017) confirm that this twenty-week period is sufficient to capture the dynamics associated with the appeals. There is no evidence of significant differences in donation (relative to baseline) after this time. Further tests reject the presence of first-order serial correlation in the residuals from this specification.

${ }^{x}$ The thirteen member charities include the largest overseas aid charities in the UK. These attract a sizeable level of donations even during baseline periods.

xi This is consistent with Eckel et al (2007) who also report a diminishing of interest over time in the case of Katrina.

xii Previous studies (eg Brown et al) based on data from the Panel Study of Income Dynamics have only been able to look at donations on a low-frequency biennial - basis.

xiii An assumption in our analysis is that the baseline level of donations is not affected by the appeals. Scharf, Smith and Ottoni-Wilhelm (2017) show that, after each disaster appeal, donations return to the same baseline level. This supports the approach of modelling the effect of disaster appeals relative to a baseline appeal of giving. 